Article

\title{
Fabrication and Testing of an Osmotic Pressure Sensor for Glucose Sensing Application
}

\section{Nagesh Ch ${ }^{1, *}$ and Roy P. Paily ${ }^{1,2}$}

${ }^{1}$ Department of Electronics and Electrical Engineering, Indian Institute of Technology Guwahati, Assam-781039, India

${ }^{2}$ Centre for Nanotechnology, Indian Institute of Technology Guwahati, Assam-781039, India;

E-Mail: roypaily@iitg.ernet.in

* Author to whom correspondence should be addressed; E-Mail: nagesh403@ gmail.com;

Tel.: +91-36-1258-2541.

Received: 12 June 2014; in revised form: 18 August 2014 / Accepted: 5 September 2014 /

Published: 18 September 2014

\begin{abstract}
This paper presents a chemical reaction-free sensor, based on the osmosis principle, fabricated to measure the change in glucose concentration levels. The sensor consists of a square cavity filled with a known concentration of glucose solution and sealed with a semi-permeable membrane. The volume inside the cavity changes in proportion to the glucose concentration outside the device and introduces the displacement in the silicon (Si) membrane on the top. The main considerations targeted for this sensor are better response time, chemical-free nature, improved lifetime and absence of any mechanical excitations. Moreover, as the size of a system plays a major role, efforts have been taken to reduce the dimension of the presented system. The designed glucose sensor is fabricated by employing a bulk micromachining technology on a SOI (silicon on insulator) substrate. This will allow batch fabrication, as well as the integration of the electronic circuit on the same substrate. The output voltage obtained is varied from -6.7 to $22.7 \mathrm{mV}$ for the corresponding glucose concentrations ranging from 50 to $450 \mathrm{mg} / \mathrm{dL}$, respectively, after a constant osmosis duration of $15 \mathrm{~min}$. The response time obtained for the sensor is $40 \mathrm{~min}$, and it is lesser compared to similar works based on the osmosis principle.
\end{abstract}

Keywords: diabetes; glucose sensor; MEMS (micro-electro-mechanical systems); osmosis; piezoresistive pressure sensor; semi-permeable membrane 


\section{Introduction}

Diabetes mellitus is a metabolic disorder, which once diagnosed, is not reversible and is characterized by imbalance in blood glucose levels, due to the lack of insulin production from the pancreas or the inability of the body to use endogenous insulin effectively, so the regular monitoring of blood glucose levels is inevitable to manage the insulin intake. This is to avoid further complications, like heart disease, nerve damage, kidney failure, vision disorders, etc. The continuous monitoring of abnormal glucose levels in a diabetes patient is carried out by either non-invasive or minimally invasive approaches. The non-invasive method of glucose detection is observed using optical devices, by directing a light beam through the skin, to measure the properties of the reflected light. Generally, such a method has limited accuracy and reliability [1,2]. Approximately $85 \%$ of the entire biosensor market possesses electrochemical glucose biosensors [3]. One of them is fingerstick meter reading, and it would require at least 4-5 blood samples per day. This method is fast and accurate, but it is a tedious process and will be painful in the long run [4]. Minimally invasive, subcutaneously implanted electroenzymatic glucose detection devices are the most popular among all of the techniques. The change in glucose concentration is proportional either to the consumption of oxygen $\left(\mathrm{O}_{2}\right)$ or to the production of hydrogen peroxide $\left(\mathrm{H}_{2} \mathrm{O}_{2}\right)$ [5]. Electroenzymatic methods of glucose detection are simpler, faster and sensitive. This technique is the basis for a number of commercially available devices, such as the Glucose Analyzer [6], the MiniMed Paradigm Real-Time Revel System [7], the FreeStyle Insulinx Meter [8] and the Dexcom G4 Platinum [9]. The drawback of electroenzymatic detection is the irreversible consumption of glucose, and this might change the equilibrium concentration of glucose in tissue; and as a result, it affects the actual measured glucose level $[10,11]$. Moreover, the rate of glucose consumption is diffusion limited and depends on the active nature of the diffusion layer. The sensitivity of the sensor is affected greatly if there is any change in the diffusion layer during the chemical process. Other drawbacks of this method are the interference from the electrode-active chemicals (such as ascorbic acid, catechol, uric acid and acetaminophen) during $\mathrm{H}_{2} \mathrm{O}_{2}$ production [12] and a shorter device life $[4,13,14]$. The enzyme glucose oxidase (GOx)-based micromachined silicon cantilever has been fabricated and demonstrated successfully [12]. The basic principle is similar to electroenzymatic detection, but instead of measuring the $\mathrm{O}_{2}$ consumption or the production of $\mathrm{H}_{2} \mathrm{O}_{2}$, the deflection due to the surface stress is analyzed to quantify the glucose concentration levels $[15,16]$. A major advantage of this technique is the selectivity, because of the high selectivity of GOx. Moreover, the response of the device is degraded when the experiment is repeated multiple times, and it may be due to the corrosive effect of $\mathrm{H}_{2} \mathrm{O}_{2}$ on the enzyme layer. The above-mentioned drawbacks of electroenzymatic detection motivated the researchers to investigate a chemical-free glucose sensor.

In 1996, Nagakura et al. [17] fabricated a chemical-free, autoregulated osmotic pump for insulin delivery. The use of osmotic energy is successfully demonstrated to provide mechanical actuation in a microactuator for drug delivery applications [18]. Many different kinds of osmotic pressure sensors are investigated, and some of them have been fabricated for potential biomedical applications, such as glucose monitoring and drug deliver [19-23]. An osmotic pump can delivery the insulin according to the change in glucose concentration levels [17]; however, their size is large (21 $\mathrm{mm} \times 20 \mathrm{~mm})$, and it is made from a polymer material. The osmosis principle is further exploited to develop an implantable devices 
for estimating glucose levels [24]. The device consists of two pressure sensors, each sensor measuring the pressure in the corresponding chamber with respect to the volume change due to the in/out flow across the membrane. Moreover, the glucose concentration levels are quantified, such that the signal of interest is the difference between the two pressure sensors. Further information on this patent is not available; however, it is possible that the sensitivity and accuracy may be limited, because the glucose concentration levels are measured in terms of the change in capacitance, which is very small compared to the fixed capacitance. Another glucose sensor based on volume change due to the flow of water across the semi-permeable membrane has been developed [25]; but, the device is large in size, and its accuracy can be improved. In another approach, smart hydrogels are confined inside a pressure sensor to facilitate the measurement of the change in glucose concentration levels [26-28]. Though its response time is high, the inclusion of smart hydrogels offers high sensitivity and selectivity. The present work focuses on an osmotic pressure sensor, which utilizes the osmosis principle to measure the glucose concentration levels, and the main considerations targeted are better response time, chemical-free nature, improved lifetime and avoidance of any mechanical excitations. Moreover, as the size of a system plays a major role [19], efforts have been taken to reduce the dimension of the presented system. The osmotic pressure sensor is fabricated by employing a bulk micromachining technology on an SOI (silicon on insulator) substrate. This will allow batch fabrication, as well as the integration of an electronic circuit on the same substrate. This paper is further organized as follows. The design and fabrication of a glucose sensor are presented in Sections 2 and 3, respectively. Finally, the device testing and performance comparison are discussed in Section 4.

\section{Design of the Glucose Sensor}

The glucose sensor utilizes the osmosis principle to measure the change in glucose concentration levels. Osmosis is defined as the net movement of solvent flow across a semipermeable membrane driven by a difference in concentration levels, as shown in Figure 1 [29]. Due to the concentration gradient, osmotic pressure develops, and the water molecules move from the lower concentration region to the higher concentration region, as indicated by the arrows. The osmotic pressure is related to the concentration of solute particles, and a mathematical relationship is formulated by Van't Hoff [30]. The osmotic pressure due to the solute concentration is given in Equation (1):

$$
\Delta \pi=R T \Delta C
$$

the $\Delta C$ is the concentration gradient $(\mathrm{mg} / \mathrm{dL}), R$ is the gas constant $(8.3145 \mathrm{~J} / \mathrm{K} \cdot \mathrm{mol})$ and $T$ is the temperature $(K)$. Equation (2) describes the rate of water flow, driven by the osmotic pressure gradient $(\Delta \pi)$, since the hydrostatic pressure $(\Delta P)$ is negligible small in the beginning [21,31]:

$$
J_{v}=K_{p} A(\sigma \Delta \pi-\Delta P)
$$

Here, $K_{p}$ is the filtration coefficient $\left(\frac{m^{3}}{N \cdot s}\right), J_{v}$ is the volume flow of water transported per unit time $\left(\mathrm{m}^{3} / \mathrm{t}\right)$, $A$ is the effective surface area of the membrane $\left(\mathrm{m}^{2}\right), \sigma$ is reflection coefficient of membrane and $\Delta \pi$ (Pa) and $\Delta P(\mathrm{~Pa})$ are the differences in osmotic and hydrostatic pressure, respectively. 
Figure 1. Water transportation across a semi-permeable membrane.

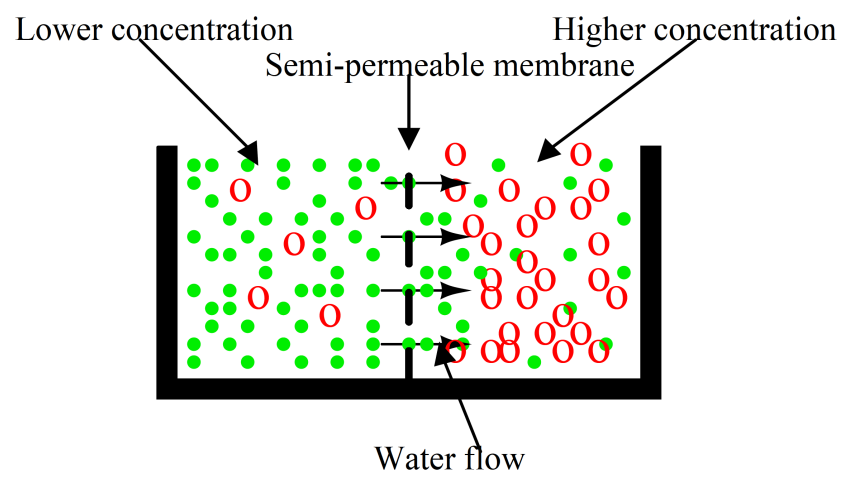

Figure 2 shows the schematic diagram of the glucose sensor. The pressure sensor is packaged using a polycarbonate material. The packaged pressure sensor is attached to a fluidic test chamber, and its size is very large compared to the device. The fluidic test chamber volume is kept around $60 \mathrm{~mL}$ compared to the device volume of $4.275 \mu \mathrm{L}$, in order to maintain the glucose concentration in the test chamber constant during the process. The pressure sensor has a square cavity, which is constructed on an SOI substrate by using bulk Si micromachining technology. Moreover, Si has excellent mechanical properties, which are required for reproducible elastic deformations under identical loads [32]. The deep reactive ion etching (DRIE) technique is used to etch the bulk Si from the back side to form a square cavity with a depth of $475 \pm 2 \mu \mathrm{m}$ and a Si diaphragm of dimensions $3.0 \mathrm{~mm} \times 3.0 \mathrm{~mm} \times 10 \mu \mathrm{m}$. The square cavity is filled with a standard glucose solution at a reference concentration. A Si membrane is constructed on the top side, and a semi-permeable membrane is used to seal the filled cavity on the bottom side. When the device is exposed to glucose solution in the fluidic test chamber, due to osmosis, the solvent (water) diffuses into the higher concentration side if there is a concentration difference across the semi-permeable membrane. The in/out flow of solvent through the semi-permeable membrane introduces the volume change inside the cavity, which causes a deflection in thin Si membrane (a thickness of $10 \mu \mathrm{m}$ ), compared to the firm semipermeable membrane (a thickness of $178 \mu \mathrm{m}$ ). The displacement of a square membrane is determined for the external pressure with the following Equation (3) [33].

$$
\frac{P l^{4}}{E h^{4}}=\frac{4.2}{1-v^{2}}\left(\frac{d}{h}\right)+\frac{1.58}{1-v}\left(\frac{d}{h}\right)^{3}
$$

where $d$ is the maximum displacement $(\mu \mathrm{m}), E$ is Young's modulus $(\mathrm{Pa}), v$ is Poisson's ratio, $h$ is the thickness of the membrane $(\mu \mathrm{m}), P$ is the pressure $(\mathrm{Pa})$ and $l$ is half of the side length of the membrane $(\mathrm{mm})$. The resultant displacement of the Si membrane due to the volume change inside the cavity is measured in terms of resistance change, by the piezoresistors, which are diffused on the top side of Si membrane. Finally, the change in glucose concentration in the test chamber introduces a stress in the Si membrane, and the corresponding output voltage variation across the Wheatstone bridge is obtained by Equation (4) [34]:

$$
\frac{V_{o}}{V_{s}}=\left(0.195 \times 10^{-9}\right)\left(\frac{L}{h}\right)^{2}\left(\frac{W_{R}}{L_{R}}\right) P
$$

where $L$ is the length of the Si membrane $(\mathrm{mm}), h$ is the thickness of the membrane $(\mu \mathrm{m}), W_{R}(\mu \mathrm{m})$ and $L_{R}(\mu \mathrm{m})$ are the width and length of the piezoresistors, respectively, $V_{o}$ is the output voltage and $V_{s}$ is the input voltage. 
Figure 2. Glucose sensor based on the osmosis principle. Inside the square cavity, a reference glucose solution of $100 \mathrm{mg} / \mathrm{dL}$ is placed. Inside the test chamber, the glucose solution is varied from $50 \mathrm{mg} / \mathrm{dL}$ to $450 \mathrm{mg} / \mathrm{dL}$.

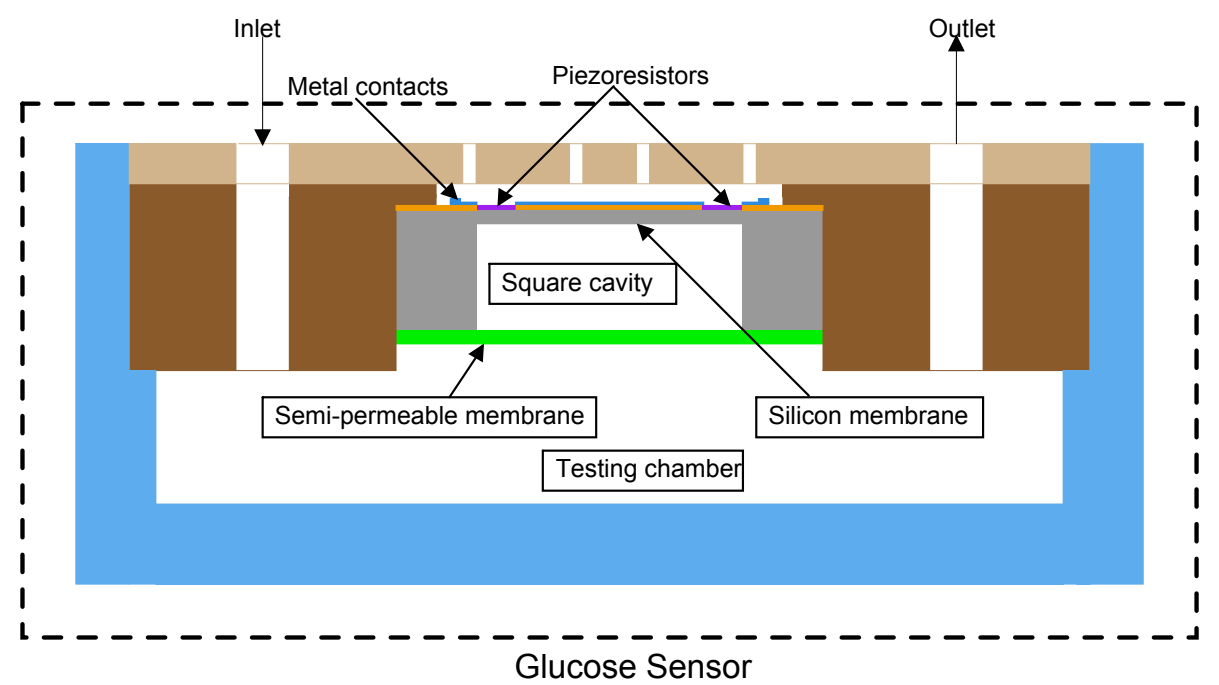

\section{Fabrication Process}

The piezoresistive pressure sensor is fabricated on an N-type (100), double-side, polished SOI substrate. The masks for the piezoresistors, back side etching and contact pads are graphically designed and written using a laser writer. Figure 3 shows the cross-sectional view of the wafer after some of the major steps involved in the fabrication.

The starting substrate is an SOI wafer of a thickness of $485 \pm 2 \mu \mathrm{m}$, approximately, and it includes a $10-\mu \mathrm{m}$ silicon at the top and $2 \mu \mathrm{m} \mathrm{SiO}_{2}$. The dimensions were verified using an optical profilometer. The wafer size was six inches, but it has been diced into smaller portions of $2-3$ in. to make the devices. The resulting cross-sectional view of a single device is shown in Figure 3a. The wafers are cleaned using piranha solution and dipped in dilute hydrofluoric (HF) acid to remove any native oxide present. A thermal oxidation (dry-wet-dry oxidation sequence) step is carried out, at $1100{ }^{\circ} \mathrm{C}$ for $210 \mathrm{~min}$, to grow a $\mathrm{SiO}_{2}$ layer on the $\mathrm{Si}$ surface, as shown in Figure 3b. The measured oxide thickness (by ellipsometer) is $1.12 \mu \mathrm{m}$, which is close to the targeted thickness of $1 \mu \mathrm{m}$. This oxide layer serves two purposes: one is as an isolation between piezoresistors and the other is as a mask for the subsequent boron diffusion process.

The wafer is subjected to the first lithography step, in order to transfer the patterns for boron diffusion. The wafers are dehydrated, and a positive photoresist (PPR) is coated on front side of the wafer, over $\mathrm{SiO}_{2}$. The wafers are pre-baked, and patterns are transferred onto the substrate with a constant UV dose of $95 \mathrm{~mJ} / \mathrm{cm}^{2}$. The developed wafer is wet etched with buffered HF (BHF) acid to remove an oxide in the opened windows, as shown in Figure 3c. The oxide on the back side was not removed, as it would act as a protection mask during the subsequent bulk Si etching. The back side oxide is covered with wax for additional protection. Figure $3 \mathrm{c}$ shows that the oxide is etched only in the windows opened for boron diffusion. If careful, one can observe the culmination of oxide removal with the naked eye, because the hydrophilic oxide will change to a hydrophobic silicon surface. The same was confirmed by a microscope, as well. 
Figure 3. The cross-sectional view of the wafer after some of the major steps: (a) starting SOI wafer; (b) growth of $\mathrm{SiO}_{2}$ layer on $\mathrm{Si}$; (c) lithography and oxide etching to make windows for piezoresistors; (d) boron diffusion; (e) $\mathrm{SiO}_{2}$ deposition using plasma enhanced chemical vapor deposition (PECVD); (f) lithography and $\mathrm{SiO}_{2}$ etching to make a window for back side Si etching; (g) bulk Si etching using deep reactive ion etching (DRIE); (h) aluminum deposition; (i) aluminum etching; and (j) top view of the metal contacts.

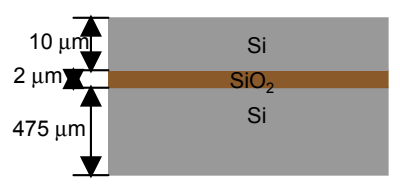

(a)

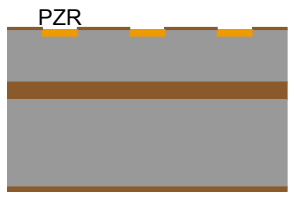

(d)

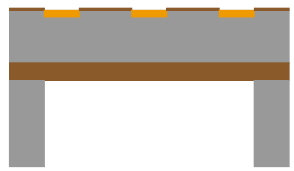

(g)

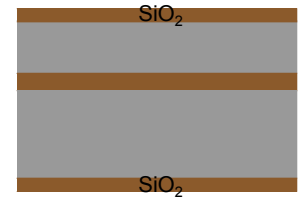

(b)

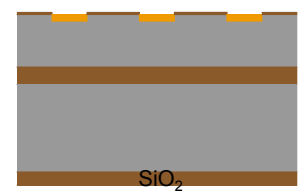

(e)

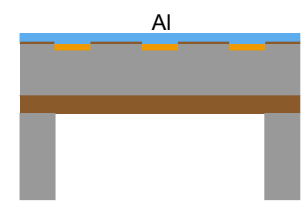

(h)

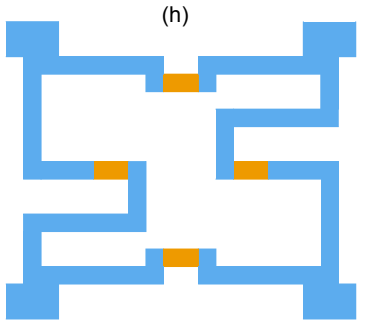

(j)

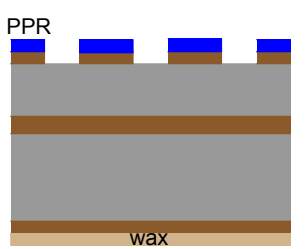

(c)

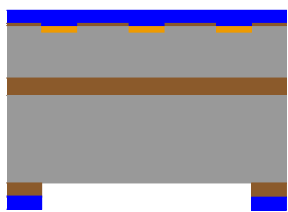

(f)

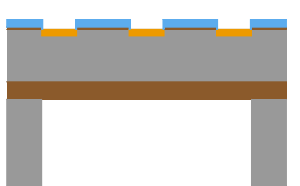

(i)

P-type Si single-crystal piezoresistors are formed by boron diffusion, as shown in Figure $3 \mathrm{~d}$. The piezoresistive coefficients for the $\mathrm{P}$-type $\mathrm{Si}$ are high compared to the $\mathrm{N}$-type $\mathrm{Si}$. Boron diffusion is carried out in a thermal furnace using the ceramic source of a boron nitride (BN) disk. Initially, a constant source diffusion is carried out at $950{ }^{\circ} \mathrm{C}$ for $15 \mathrm{~min}$ in the $\mathrm{N}_{2}$ (two liters/minute) ambient to place a known dose in a shallow layer on the surface of the Si. The borosilicate glass (BSG) deposited on the wafer during the constant source diffusion is removed using the BHF. The sheet resistance after the pre-deposition is $98.51 \mathrm{ohm} / \mathrm{sq}$ approximately. The boron is diffused deeper into the Si wafer during a subsequent high-temperature limited-source diffusion (or drive-in) step. The oxide grown during the annealing is removed using a BHF solution. The sheet resistance is measured after the drive-in is $158 \mathrm{ohm} / \mathrm{sq}$ approximately. The thermally-grown oxide on the back side has been thinned down during the etching of the BSG, as shown in Figure 3d. In order to etch the bulk Si using the DRIE, the oxide mask needs to be thicker. The $\mathrm{SiO}_{2}$ layer is deposited on the back side using a plasma enhanced chemical vapor deposition (PECVD). The total oxide thickness measured (by ellipsometer) is $1.5 \mu \mathrm{m}$, as shown in Figure 3e.

A second lithography step is employed to transfer the patterns to the back side of the substrate, to facilitate the etching of bulk Si. Using a double-side alignment technique, Mask 2 is aligned to the top 
side of wafer corresponding to the alignment marks formed during the previous boron diffusion, and the wafer is exposed to UV for five seconds. The oxide is etched from the opened windows using the reactive ion etching (RIE) Technique. The resultant cross-section is show in Figure $3 \mathrm{f}$. The DRIE is used to etch the bulk Si from the back side, to form a square cavity reaching till the oxide layer. The $\mathrm{Si}$ is etched with two different recipes: the etch rate for the first recipe is $28-29 \mu \mathrm{m} / \mathrm{min}$, and it is carried out for $15 \mathrm{~min}$; the second recipe is $2-3 \mu \mathrm{m} / \mathrm{min}$ and it is carried for $10 \mathrm{~min}$. The Si etching is stopped exactly at the buried oxide layer, as shown in Figure $3 \mathrm{~g}$.

The next step is a metallization, to provide the metal contacts for the piezoresistors. Two hundred nanometer-thick aluminum is deposited on the top of wafer by thermal evaporation, as shown in Figure $3 \mathrm{~h}$. After the deposition of aluminum, the wafers are annealed in forming gas in order to reduce the resistance of the metal contacts as a result of the expansion of the crystal grain boundaries. A third lithography step is employed to transfer the patterns for the metal contacts. Before coating the photoresist on the top side of the substrate, the wafers are mounted on a dummy wafer, to avoid any breakage of the very thin diaphragm. The wafers are exposed to UV at a constant dose of $95 \mathrm{~mJ} / \mathrm{cm}^{2}$ and developed to remove the photoresist from the exposed areas, as shown in Figure 3i. Aluminum etching is carried out at room temperature with an etchant (wet etching), and the metal contacts connected to the piezoresistors can be seen in Figure 3j.

\section{Experimental Results and Discussion}

In this section, the results of the fabricated glucose sensor are presented first, followed by a comparison to other reported glucose sensors. A test setup, as shown in Figure 4, is prepared for the glucose sensor to measure any change in glucose concentration levels. The square cavity on the bottom side of the glucose sensor is cleaned using acetone and is followed by isopropyl alcohol (IPA) to remove any dust particles. White crystal powder of D-glucose $\left(\mathrm{C}_{6} \mathrm{H}_{12} \mathrm{O}_{6}\right)$ is used to prepare glucose solutions by adding the required amount of high purity deionized (DI) water. A glucose concentration of $100 \mathrm{mg} / \mathrm{dL}$ is prepared by adding $100 \mathrm{mg}$ of D-glucose in $100 \mathrm{~mL}$ of DI water. A series of glucose solutions are prepared, having concentrations ranging from 50 to $450 \mathrm{mg} / \mathrm{dL}$, by adding suitable amounts of D-glucose (i.e., 50 to $450 \mathrm{mg}$ ) into $100 \mathrm{~mL}$ of DI water.

Before the cavity is filled with any solution, the output voltage across the Wheatstone bridge is about $1 \mathrm{mV}$. To begin the testing, the square cavity is filled with a standard glucose concentration of $100 \mathrm{mg} / \mathrm{dL}$. Please note that the device is not attached to the test chamber at this time. Then, the device is sealed with semi-permeable membrane using super glue. The semi-permeable membrane (YMCESP3001, Sterlitech Corporation, Kent, OH, USA) employed is of a cellulose acetate material having properties, such as $97 \%$ of $\mathrm{NaCl}$ rejection and a $\mathrm{pH}$ range of $2-8$. The molecular weight cut off (MWCO) of membrane is zero. The MWCO defines the smallest solute that will pass through a membrane, and larger particles above the MWCO are rejected. The molecular weight of $\mathrm{NaCl}$ and glucose are 58.44 and $180.16 \mathrm{~g} / \mathrm{mol}$, respectively, and these molecules may not pass through the membrane. The thickness and Young's modulus of the membrane are $178 \mu \mathrm{m}$ and $12.781 \pm 2 \mathrm{GPa}$, respectively. The empty porous portions of the membrane is filled with solvent once the semi-permeable membrane comes into contact with the filled cavity, and subsequently, the membrane becomes wet. Though we have introduced a 100-mg/dL 
solution to the chamber, some solvent is already absorbed by the membrane; therefore, the volume inside the cavity is decreased, and its glucose concentration is also increased. This causes a displacement in the membrane towards the cavity, and the output voltage is increased to $19.2 \mathrm{mV}$. Then, the device is attached with fluidic test chamber, as shown in Figure 4. To characterize the device response time, the glucose concentration in the square cavity needs to be reset to the reference value of $100 \mathrm{mg} / \mathrm{dL}$, i.e., the output voltage needs to be brought back to the reference value close to zero. For this purpose, a glucose solution of $100 \mathrm{mg} / \mathrm{dL}$ is introduced into the test chamber, where it is allowed to permeate through the semi-permeable membrane, to interact with the standard glucose solution in the device. The solvent moves from the test chamber into the device cavity, in order to balance the osmotic pressure. The voltage is decreased from 19.2 to $1.1 \mathrm{mV}$ within $25 \mathrm{~min}$. It has been observed that for the next $20 \mathrm{~min}$, the variation in the output voltage is negligibly small and reached the reference point (close to zero) after 45 min, as shown in Figure 5. The fluid volume of the test chamber is made very high compared to the device cavity volume, such that the concentration in the test chamber will be constant during the osmosis process. In a separate measurement, a glucose concentration of $100 \mathrm{mg} / \mathrm{dL}$ is placed in the test chamber for $720 \mathrm{~min}$, and the output voltage obtained was constant for the entire duration.

Figure 4. Glucose sensor with a testing chamber attached on the bottom side.

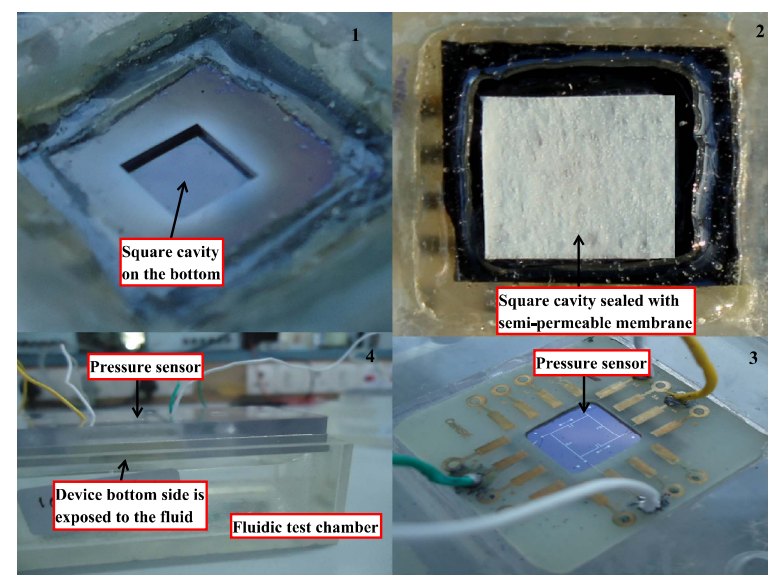

Figure 5. The output voltage is decreased when the $100 \mathrm{mg} / \mathrm{dL}$ glucose concentration is introduced in the test chamber.

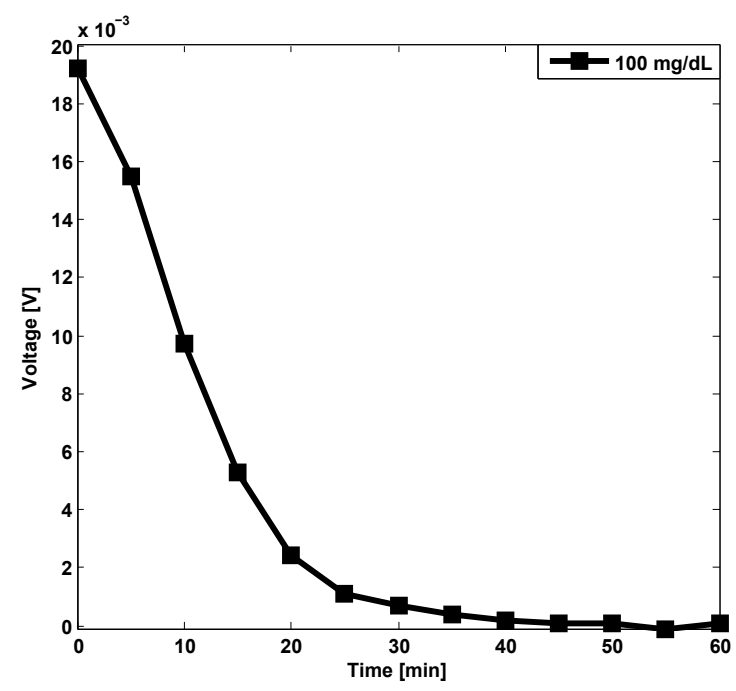


Next, the test chamber that contains a glucose solution of $100 \mathrm{mg} / \mathrm{dL}$ is replaced with another liquid under test (in this case, a 150-mg/dL solution). Now, the glucose concentration inside the device cavity is $100 \mathrm{mg} / \mathrm{dL}$, and it is $150 \mathrm{mg} / \mathrm{dL}$ in the test chamber. The concentration difference is $50 \mathrm{mg} / \mathrm{dL}$ across the semi-permeable membrane, and the corresponding osmotic pressure is developed as per Equation (2). This causes a net flow of solvent from the sensor cavity, which contains a lower concentration (hypotonic solution), into the test chamber having a higher concentration (hypertonic solution). The volume inside the cavity decreases as the solvent flows through the semi-permeable membrane into the test chamber, and it causes a displacement in the Si membrane. The resultant change in output voltage corresponds to a $150-\mathrm{mg} / \mathrm{dL}$ glucose concentration, is continuously monitored and, finally, reaches a maximum value of $20.7 \mathrm{mV}$ after $40 \mathrm{~min}$, and for a further $10 \mathrm{~min}$, the variation observed is negligible, as shown in Figure 6a. The response time of an osmosis sensor is characterized as the time required to attain $95 \%$ of its steady-state value of the output voltage for the change in glucose concentration in the test chamber (for example $150 \mathrm{mg} / \mathrm{dL}$ ) [10]. As a result, the glucose concentration inside the device cavity is increased from a reference value $(100 \mathrm{mg} / \mathrm{dL})$ to another value, which will be less than $150 \mathrm{mg} / \mathrm{dL}$. When the $150-\mathrm{mg} / \mathrm{dL}$ glucose concentration in the test chamber is replaced with $100 \mathrm{mg} / \mathrm{dL}$, the output voltage is decreased monotonously towards the original reference point, as shown in Figure 6b. When the test chamber is filled with $100 \mathrm{mg} / \mathrm{dL}$, the time taken to reach the reference point is approximately $90 \pm 15 \mathrm{~min}$, and it is very high compared to the response time of the sensor, which is $40 \mathrm{~min}$, because the osmotic pressure difference is less. The sensitivity of the glucose sensor is the desired output (voltage in this case) per $\mathrm{mg} / \mathrm{dL}$ of glucose concentration with respect to time and input source. Including the DC (direct current) source and time, the sensitivity (output voltage per ( $\mathrm{mg} / \mathrm{dL}$ ) per voltage per time) obtained is approximately $2 \mu \mathrm{V} /(\mathrm{V} \cdot \mathrm{mg} / \mathrm{dL} \cdot \mathrm{min})$, without any amplification of the output voltage.

The glucose sensor is tested with different glucose concentrations, ranging from 50 to $450 \mathrm{mg} / \mathrm{dL}$. Figure 7 shows the output voltage of the glucose sensor for the different glucose concentrations. If Figure 7 is extended till the settling time, the plots will be too crowded, and hence, a format, like in Figure 8 , is opted for, for better visibility. In each case, the concentration inside the cavity is reset to $100 \mathrm{mg} / \mathrm{dL}$ prior to the measurement of a new glucose solution in the test chamber. The time needed to reach the maximum value of the output voltage is different for each concentration, and it is shortest for the case where the test chamber contains the highest concentration of glucose, as shown in Figure 8 . The difference in glucose concentration across the the semi-permeable membrane with respect to the reference point of $100 \mathrm{mg} / \mathrm{dL}$ is shown on the $x$-axis. For instance, when the glucose solution in the test chamber is $450 \mathrm{mg} / \mathrm{dL}$, the output voltage attains its steady-state value within $15 \mathrm{~min}$, as shown in Figure 7. When the concentration is increased from 50 to $450 \mathrm{mg} / \mathrm{dL}$, the output voltage across the Wheatstone bridge is increased from -6.7 to $22.7 \mathrm{mV}$, as shown in Figure 9. For each concentration, a constant duration of $15 \mathrm{~min}$ is kept for osmosis to occur. Figure 9 summarizes the device behavior and provides a quantitative measure of the glucose concentration in terms of voltage. The output voltage indicated in each case is the value obtained after $15 \mathrm{~min}$ of osmosis. The error bars indicate the variation observed during three consecutive measurements. The sensitivity obtained is in the range of 1 to $2 \mu \mathrm{V} /(\mathrm{V} \cdot \mathrm{mg} / \mathrm{dL} \cdot \mathrm{min})$, without amplification of the output voltage, for the corresponding glucose concentrations ranging from $50-450 \mathrm{mg} / \mathrm{dL}$. The device is tested continuously for eight days with different concentrations to verify the endurance of the device. The variation in the output voltage 
is always found to be proportional to the glucose concentration change. All of the above measurements are carried out in a room temperature ambient atmosphere $\left(26\right.$ to $\left.28^{\circ} \mathrm{C}\right)$.

Figure 6. (a) The response of a sensor for the glucose solution of $150 \mathrm{mg} / \mathrm{dL}$ when the concentration inside the cavity is $100 \mathrm{mg} / \mathrm{dL}$; and (b) for this case, when the glucose solution in the test chamber is replaced with $100 \mathrm{mg} / \mathrm{dL}$, the output voltage is decreasing towards the original reference point.

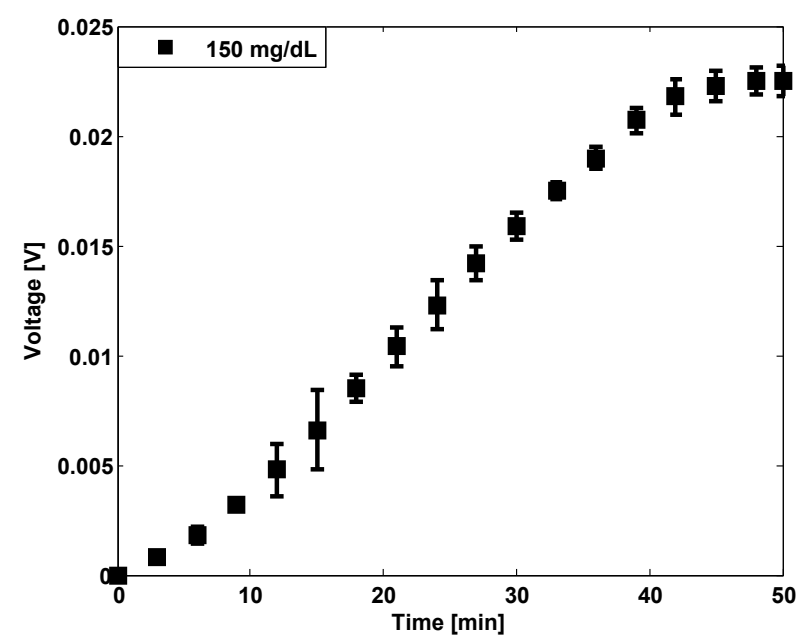

(a)

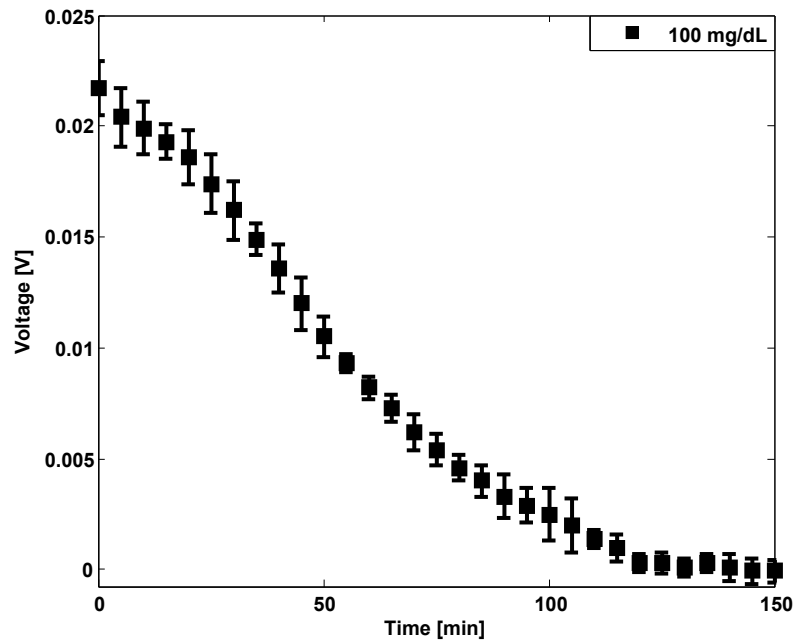

(b)

Figure 7. The output voltage as a function of time, for different glucose concentrations in the test chamber.

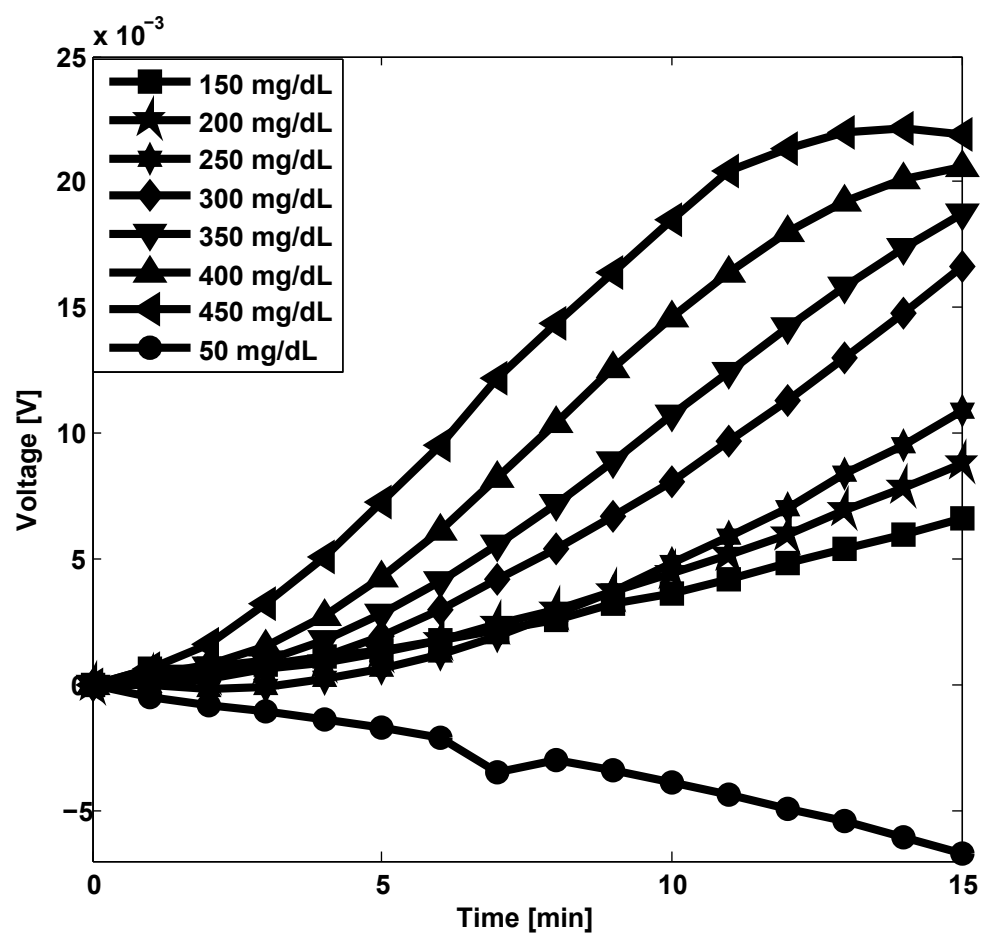


Figure 8. The response time of the glucose sensor for the concentration difference across the semi-permeable membrane.

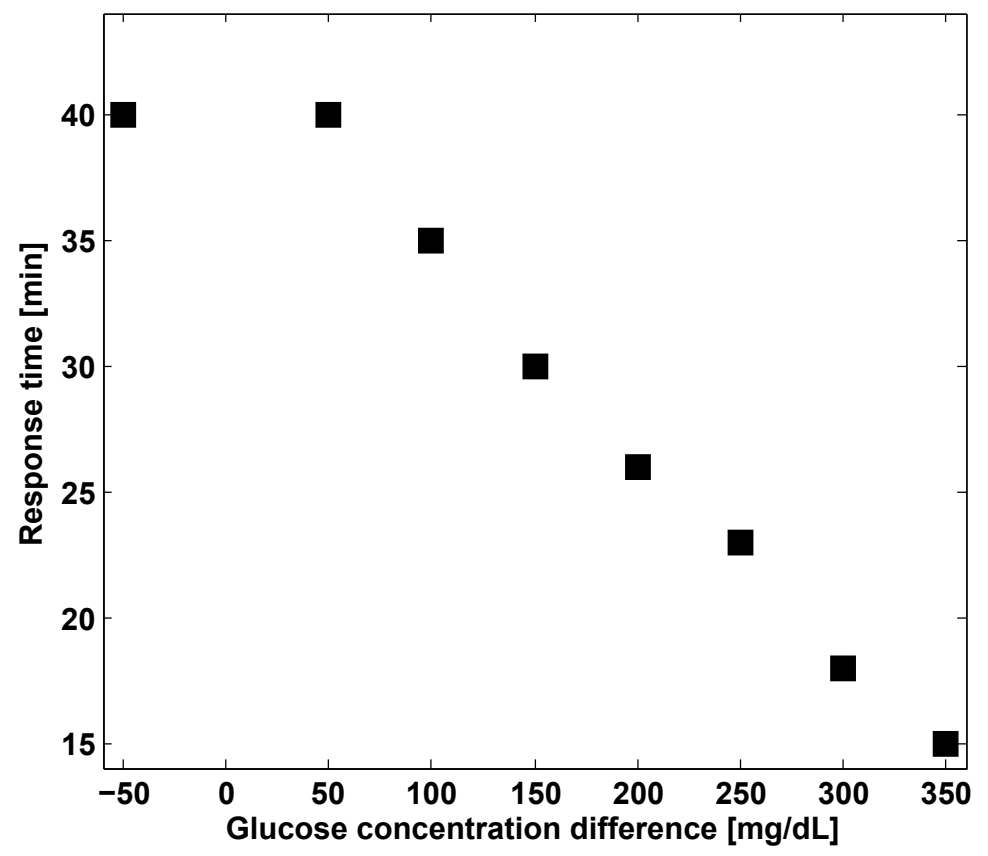

Figure 9. The output voltages obtained after $15 \mathrm{~min}$ of osmosis for different glucose concentrations. The error bars indicate the variation observed during three consecutive measurements.

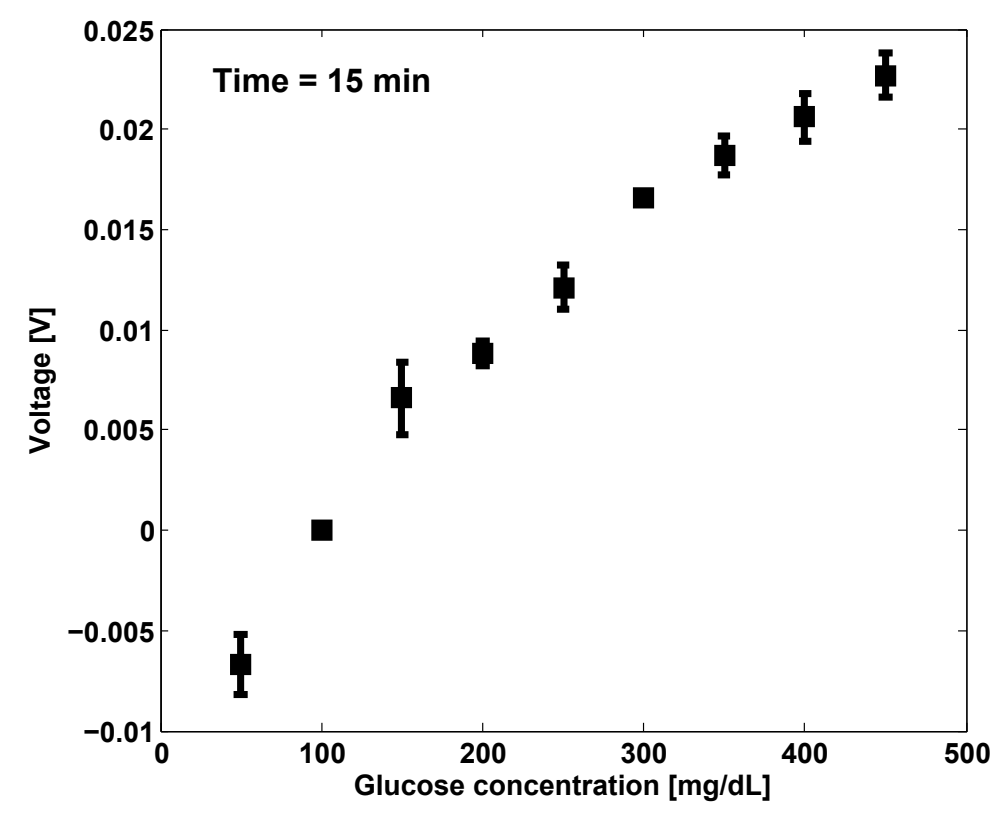

The fabricated glucose sensor is able to measure a small variation (results for $50 \mathrm{mg} / \mathrm{dL}$ are plotted, but it could be as low as $20 \mathrm{mg} / \mathrm{dL}$ ) in the glucose concentration levels. The performance comparison of the fabricated glucose sensors are presented in Table 1 . The response time of the present glucose sensor is $40 \mathrm{~min}$, which is lower compared to other reported works in [17,26]. In the present work, the ratio of fluid volume change inside the cavity to the total volume of the cavity is high compared to the sensor 
in [17], and therefore, the response time is shorter. Nevertheless, the response time of the present work is much higher when compared to a value of $1.5 \mathrm{~min}$ reported in [10,11]. The response time is much smaller in those glucose affinity sensors $[10,11,35]$, because the time needed for the glucose molecule to associate/dissociate with the polymer is smaller. The response time is high for the glucose sensor in [26], even though it involves chemical binding, due to the expansion or contraction time required for the hydrogel. In the case of the glucose affinity smart hydrogel, glucose solute molecules permeate through membrane $[10,11,26]$, where in the present work, the solvent molecules flow through the semi-permeable membrane. Moreover, the present work is related to the volume change inside the cavity with respect to the change in glucose concentrations, which finally brings a deflection in the Si membrane, and like in [10-12,26,35], neither any chemical reactions nor any mechanical excitation's are involved, so that the lifetime of the device is improved. The sensing mechanism employed in the present work is very simple compared to the other glucose sensing devices, as the variations in the glucose concentration levels are directly measured in terms of voltage, with the help of a simple Wheatstone bridge and a battery. In the case of the capacitance change reported in [11,35], an external circuit is employed to convert the changes into a voltage. Another sensing mechanism is optical in nature, and the one required to detect the deflection in the cantilever beam corresponds to glucose concentrations [12]; such a method is not suitable for implantation purposes, and it is unstable in a mobile environment. Further, the present work requires very simple fabrication steps, and it is small in size compared to the sensor in [17]. The device lifetime of the present sensor is expected to be longer, since there are no chemical reactions involved.

The device might respond not only to glucose, but to similar substances, like de-hydration, ethanol, lactic-acid, amino acids, ascorbic acid and mannose [19,27], if there is a substantial change in their concentration levels, and this will cause interference. Normally, the lactic-acid concentration levels are small, but during exercise, these will rise to higher levels. The ethanol and amino acids concentration levels are related to dietary aspects, and they can be maintained in a normal range, though they cannot be controlled at a constant level. The interference from other substances needs to be addressed for the improvement of this sensor. The selectivity of this sensor may be improved by employing glucose affinity materials, like hydrogel or Concanavalin (Con) A-dextran [26-28], in the device instead of a standard solution. The sensing material employed in [27,28] consists of Con A, which possesses an affinity toward glucose, and the equilibrium is perturbed by glucose binding to lectin, triggering a dissociation of dextran that is proportional to the increase in glucose. In addition to Con A-dextran, one needs a special semi-permeable membrane that allows selective diffusion of glucose across the membrane, but that prevents the transport of larger molecules, such as peptides or proteins, or other potentially interfering molecules, such as lactate or polysaccharide, contained in body fluids [36]. Generally, cellulose acetate (CA), cellulose ester and polyamide (PA) membranes are used in glucose sensing application based on the osmosis principle [27,28,36,37]. The cellulose membranes present chemical and biological resistances to the body and are not suitable for a long-term implant. Anodic aluminum oxide (AAO) membranes have found acceptance for a wide range of bio-medical applications $[28,36]$. 
Table 1. Performance comparison of fabricated glucose sensors.

\begin{tabular}{|c|c|c|c|c|c|c|}
\hline Reference & $\begin{array}{l}\text { Basic Principle/ } \\
\text { Sensing Mechanism }\end{array}$ & Selectivity & $\begin{array}{l}\text { Any Mechanical } \\
\text { Excitations } \\
\text { Involved? }\end{array}$ & $\begin{array}{l}\text { Measurement } \\
\text { Quantity } \\
\text { and Instruments }\end{array}$ & $\begin{array}{l}\text { Response Time } \\
(\min )\end{array}$ & $\begin{array}{l}\text { Device Dimensions } \\
(\mu \mathrm{m})\end{array}$ \\
\hline [10] & $\begin{array}{l}\text { Association/dissociation } \\
\text { (Viscosity change) }\end{array}$ & Yes & $\begin{array}{l}\text { Magnetic } \\
\text { excitation }\end{array}$ & $\begin{array}{l}\text { Deflection is } \\
\text { converted to voltage } \\
\text { (Optical lever system } \\
\text { and photodetector) }\end{array}$ & 3 & $\begin{array}{l}\sim(600 \times 600 \times 800) \\
\text { Rectangular cuboid }\end{array}$ \\
\hline [11] & $\begin{array}{l}\text { Association/dissociation } \\
\text { (Viscosity change) }\end{array}$ & Yes & $\begin{array}{l}\text { Magnetic } \\
\text { excitation }\end{array}$ & $\begin{array}{l}\text { Capacitance is } \\
\text { converted to voltage } \\
\text { (Built-in capacitor) }\end{array}$ & 1.5 & $\begin{array}{l}500 \times \sim 500 \times \sim 530 \\
\text { Rectangular cuboid }\end{array}$ \\
\hline [12] & $\begin{array}{l}\mathrm{O}_{2} \text { consumption } \\
\text { and production } \mathrm{H}_{2} \mathrm{O}_{2} \\
\text { (Surface stress change) }\end{array}$ & Yes & No & $\begin{array}{l}\text { Deflection } \\
\text { (Atomic force microscope } \\
\text { and position } \\
\text { sensitive detector) }\end{array}$ & $\sim 40$ & $\begin{array}{l}350 \times 35 \times 1 \\
\text { Cantilever }\end{array}$ \\
\hline [17] & $\begin{array}{l}\text { Osmosis } \\
\text { (Volume change) }\end{array}$ & No & No & $\begin{array}{l}\text { Displacement (Laser } \\
\text { displacement meter) }\end{array}$ & 120 & $\begin{array}{l}21,000 \times 20,000 \\
\text { Cylindrical }\end{array}$ \\
\hline [26] & $\begin{array}{l}\text { Association/dissociation } \\
\text { (Pressure change) }\end{array}$ & Yes & No & $\begin{array}{l}\text { Pressure (Piezoresistive } \\
\text { pressure transducer) }\end{array}$ & $60 \pm 15$ & $\begin{array}{l}3,180 \times \sim 420 \\
\text { Cylindrical }\end{array}$ \\
\hline Present work & $\begin{array}{l}\text { Osmosis } \\
\text { (Volume change) }\end{array}$ & No & No & $\begin{array}{l}\text { Voltage (Built-in } \\
\text { Wheatstone bridge) }\end{array}$ & 40 & $\begin{array}{l}3,000 \times 3,000 \times 650 \\
\text { Square cuboid }\end{array}$ \\
\hline
\end{tabular}




\section{Conclusions}

The concept of an osmosis-based pressure sensor is extended to a specific application of glucose sensing. We have demonstrated a device to measure changes in glucose concentrations outside with respect to the reference solution of $100 \mathrm{mg} / \mathrm{dL}$ inside the cavity. A system in which a piezoresistive pressure sensor was attached to a fluidic test chamber and a test setup were prepared to measure the glucose concentration levels in the test chamber. The device was tested with different glucose concentrations ranging from 50 to $450 \mathrm{mg} / \mathrm{dL}$, and the output voltage of the glucose sensor was increased from -6.7 to $22.7 \mathrm{mV}$. The response time obtained was found to be less, and the variation in the output voltage was proportional to the glucose concentration change in the chamber. The fabrication process was simple, and the the sensor has an improved life time, because there were no chemical reactions or external excitations involved.

\section{Acknowledgments}

The fabrication of the glucose sensor was carried out at Centre for Nano Science and Engineering (CeNSE), Indian Institute of Science Bangalore, through the Indian Nanoelectronics Users Program (INUP) funded by Department of Information Technology (DIT), Government of India. The authors would like to thank K. N. Bhat and the staff members of CeNSE for their constant support during the fabrication process.

\section{Author Contributions}

Nagesh Ch performed the design, fabrication, experiments, and analyzed the data, and draft is prepared. Roy P. Paily contributed to the original idea of this study, and supervised the entire work and the manuscript is finalized.

\section{Conflicts of Interest}

The authors declare no conflict of interest.

\section{References}

1. Koschinsky, T.; Heinemann, L. Sensors for glucose monitoring: Technical and clinical aspects. Diab. Metab. Res. Rev. 2001, 17, 113-123.

2. Pickup, J.C.; Hussain, F.; Evans, N.D.; Rolinski, O.J.; Birch, D.J.S. Fluorescence-based glucose sensors. Biosen. Bioelectron. 2005, 20, 2555-2565.

3. Wang, J. Electrochemical glucose biosensors. Chem. Rev. 2008, 108, 814-825.

4. Takahashi, D.; Xiao, Y.; Hu, F.; Lewis, M. A Survey of insulin-dependent diabetes-Part I: Therapies and devices. Int. J. Telemed. Appl. 2007, 2008, 1-15.

5. Updike, S.; Hicks, G. The enzyme electrode. Nature 1967, 214, 986-988.

6. YSI 2300 STAT Plus ${ }^{T M}$ Glucose \& Lactate Analyzer. Available online: http://www.ysilifesciences. com/index.php?page=ysi-2300-stat-plus-glucose-lactate-analyzer (accessed on 10 April 2014). 
7. MiniMed Paradigm Real-Time Revel ${ }^{T M}$ System. Available online: http://www.minimed.com /products/insulinpumps/index.html (accessed on 9 June 2014).

8. FreeStyle Insulinx Meter. Available online: http://www.abbottdiabetescare.com (accessed on 10 April 2014).

9. Dexcom G4 Platinum. Available online: http://www.dexcom.com/ (accessed on 9 June 2014).

10. Huang, X.; Li, S.Q.; Schultz, J.; Wang, Q.; Lin, Q. A MEMS affinity glucose sensor using a biocompatible glucose-responsive polymer. Sens. Actuators B Chem. 2009, 140, 603-609.

11. Huang, X.; Li, S.Q.; Schultz, J.; Wang, Q.; Lin, Q. A capacitive MEMS viscometric sensor for affinity detection of glucose. J. Microelectromech. Syst. 2009, 18, 1246-1254.

12. Pei, J.; Tian, F.; Thundat, T. Glucose biosensor based on the microcantilever. Anal. Chem. 2004, 76, 292-297.

13. David, C.K. Continuous glucose monitoring roadmap for 21 st century diabetes therapy. Diabtes Care. 2005, 28, 1231-1239.

14. Adam, H. Implanted electrochemical glucose sensors for the management of diabetes. Ann. Rev. Biomed. Eng. 1999, 1, 153-175.

15. Pei, J.H.; Tian, F.; Thundat, T. Novel glucose biosensor based on the microcantilever. Anal. Chem. 2004, 76, 292-297.

16. Subramanian, A.; Oden, P.I.; Kennel, S.J.; Jacobson, K.B.; Warmack, R.J.; Thundat, T.; Doktycz, M.J. Glucose biosensing using an enzyme-coated microcantilever. Appl. Phy. Lett. 2002, $81,385-387$.

17. Nagakura, T.; Ishihara, K.; Furukawa, T.; Masuda, K.; Tsuda, T. Auto-regulated osmotic pump for insulin therapy by sensing glucose concentration without energy supply. Sens. Actuators B Chem. 1996, 34, 229-233.

18. Su, Y.C.; Lin, L.; Pisano, A.P. A water-powered osmotic microactuator. J. Microelectromech. Syst. 2002, 11, 736-742.

19. Ellingsen, O.; Kulseng, H.; Kristiansen, B.E. Sensor in vivo Measurement of Osmotic Changes. U.S. Patent 7,276,028 B2, 2 October 2007.

20. Su, Y.C.; Lin, L. A water-powered micro drug delivery system. J. Microelectromech. Syst. 2004, $13,75-82$.

21. Theeuwes, F.; Yum, S.I. Principles of the design and operation of generic osmotic pumps for the delivery of semisolid or liquid drug formulations. Ann. Biomed. Eng. 1976, 4, 343-353.

22. Ghosh, T.; Ghosh, A. Drug delivery through osmotic systems an overview. J. App. Pharm. Sci. 2011, $1,38-49$.

23. Lin, G.; Chang, S.; Kuo, C.H.; Magda, J.; Solzbacher, F. Free swelling and confined smart hydrogels for applications in chemomechanical sensors for physiological monitoring. J. App. Pharm. Sci. 2009, 136, 186-195.

24. Naftel, F. Implantable Device for Estimating Glucose Levels. U.S. Patent 5,337,747, 16 August 1994.

25. Ellingsen, O. Method for Monitoring the Level of an Osmotically Active Component in Body Fluid and Device for Carrying Out Said Method. U.S. Patent 6,224,550 B1, 1 May 2001. 
26. Lin, G.; Chang, S.; Hao, H.; Tathireddy, P.; Orthner, M.; Magda, J.; Solzbacher, F. Osmotic swelling pressure response of smart hydrogels suitable for chronically implantable glucose sensors. Sens. Actuators B Chem. 2010, 144, 332-336.

27. Krushinitskaya, O.; Tønnessen, T.I.; Jakobsen, H.; Johannessen, E. The assessment of potentially interfering metabolites and dietar components in blood using an osmotic glucose sensor based on the concanavalin A-dextran affinity assay. Biosen. Bioelectron. 2011, 28, 195-203.

28. Johannessen, E.; Krushinitskaya, O.; Sokolov, A.; Häfliger, P.; Hoogerwerf, A.; Hinderling, C.; Kautio, K.; Lenkkeri, J.; Strömmer, E.; Kondratyev, V.; et al. Toward an injectable continuous osmotic glucose sensor. J. Diabetes Sci. Technol. 2010, 4, 882-892.

29. Vogel, S. Cats' Paws and Catapults; W.W. Norton \& Company, Inc.: New York, NY, USA, 1998.

30. Richard, P.D. Osmotic flow of water across permeable cellulose membranes. J. Gen. Physiol. 1969, $44,315-326$.

31. Cath, T.Y.; Childress, A.E.; Elimelech, M. Forward osmosis: Principles, applications, and recent developments. J. Membr. Sci. 2006, 281, 70-87.

32. Bhat, K.N. Silicon micromachined pressure sensors. J. IISc. 2007, 87, 115-131.

33. Narayanaswamy, M.; Daniel, R.J.; Sumangala, K.; Jeyasehar, C.A. Computer aided modelling and diaphragm design approach for high sensitivity silicon-on-insulator pressure sensors. Measurement 2011, 44, 1924-1936.

34. Senturia, S.D. Microsystem Design; Kluwer Academic Publishers: Dordrecht, The Netherlands, 2001.

35. Zhao, Y.; Li, S.; Davidson, A.; Yang, B.; Wang, Q.; Lin, Q. A MEMS viscometric sensor for continuous glucose monitoring. J. Micromech. Microeng. 2007, 17, 2528-2537.

36. Klok, H.A.; Lavanant, L. Selectively Permeable Coated Membrane. U.S. Patent 8,394,022 B2, 12 March 2013.

37. Krushinitskaya, O.; Tønnessen, T.I.; Jakobsen, H.; Johannessen, E.A. Characterization of nanoporous membranes for implementation in an osmotic glucose sensor based on the concanavalin A-dextran affinity assay. J. Membr. Sci. 2011, 376, 153-161.

(c) 2014 by the authors; licensee MDPI, Basel, Switzerland. This article is an open access article distributed under the terms and conditions of the Creative Commons Attribution license (http://creativecommons.org/licenses/by/3.0/). 